\title{
Internet Use in Old Age: Results of a German Population-Representative Survey
}

Janine Quittschalle ${ }^{1}$, MA; Janine Stein ${ }^{1}$, PhD; Melanie Luppa ${ }^{1}$, PhD; Alexander Pabst ${ }^{1}, \mathrm{PhD}$; Margrit Löbner ${ }^{1}, \mathrm{PhD}$; Hans-Helmut Koenig ${ }^{2}$, MPH, MD, Prof Dr; Steffi G Riedel-Heller ${ }^{1}$, MPH, MD, Prof Dr

\footnotetext{
${ }^{1}$ Institute of Social Medicine, Occupational Health and Public Health (ISAP), University of Germany, Leipzig, Germany

${ }^{2}$ Department of Health Economics and Health Services Research, University Medical Center Hamburg-Eppendorf, Hamburg, Germany
}

\section{Corresponding Author:}

Janine Quittschalle, MA

Institute of Social Medicine, Occupational Health and Public Health (ISAP)

University of Germany

Philipp-Rosenthal-Straße 55, Building W

Leipzig, 04103

Germany

Phone: 493419724571

Email: Janine.Quittschalle@ medizin.uni-leipzig.de

\section{Abstract}

Background: The internet has the potential to foster healthy lifestyles and to support chronic disease management. Older adults could benefit from using the internet and other information and communication technology to access health-related information and interventions available online.

Objective: The aim of this study was to investigate factors influencing internet use in older and oldest age groups and to determine the frequency of internet use for health-related purposes.

Methods: Using data from a nationally representative telephone survey of older adults aged 75 years and over, a sample of 999 people was assessed using structured clinical interviews. Descriptive and binary logistic regression analyses were performed.

Results: Overall, 42.6\% (418/999) of participants used the internet. Among those, 55.7\% (233/417) searched the internet for health-related information. Regression analyses revealed that internet use was significantly associated with younger age (odds ratio [OR] $0.89,95 \%$ CI 0.85-0.92; $P<.001$ ), male gender (OR 2.84, 95\% CI 2.02-4.00; $P<.001$ ), higher education levels (OR $6.69,95 \%$ CI 4.48-9.99; $P<.001$ ), a wider social network (OR 1.04, 95\% CI 1.01-1.07; $P=.01$ ), higher health-related quality of life (OR 1.02, 95\% CI 1.00-1.03; $P=.006$ ), lower levels of depressive symptoms (OR 0.89, 95\% CI 0.80-0.99; $P=.04$ ), and higher rates of chronic illness (OR 1.12, 95\% CI 1.04-1.21; $P<.004)$.

Conclusions: This study provides population-representative data on internet use in old age in Germany. People in the older and oldest age groups participate in online activities. Understanding the factors that are associated with older adults internet use can contribute to developing tailored interventions and eHealth (electronic health) services to improve well-being in older adults.

(J Med Internet Res 2020;22(11):e15543) doi: 10.2196/15543

\section{KEYWORDS}

internet use; epidemiology; old age; health services; eHealth

\section{Introduction}

\section{Background}

Aging is often associated with major changes and stressful life transitions (eg, shrinking social network, relocation, retirement) that have a big impact on well-being, health, and everyday life [1]. Researchers have highlighted the enormous benefits of internet and information and communication technology (ICT) use for the aging population. For instance, these benefits include enhancement of social connectivity [2], prevention or reduction of social isolation [3], increased information about offline leisure and recreational activities [4,5], and increased empowerment through access to information (eg, health-related issues) [6,7]. Various studies have explored factors at the individual level as well as factors of the social context that predict internet use in older age. Results have consistently shown that factors that are positively associated with internet use over 65 are younger age, 
male gender, higher educational level, married or living with someone else, specifically partners or family members [2,8-12].

However, some researchers have found fault with these findings, arguing that many studies aggregated people of a certain age together into 1 homogenous category [13], or that they did not include older age groups (eg, 70+) [12]. Few studies that focus on older adults (75+) [4,8,12,13] have analyzed sociodemographic correlates, health determinants, and social context correlates of internet use. They did, however, confirm previous results, for example, with regard to age, gender, education, and marital status. Importantly, the authors found that adults aged 75 and older use the internet less frequently than younger seniors, which led them to conclude that the "digital divide" between this age group and other population groups is more pronounced $[12,14]$. Because of the benefits of digital technologies for older adults, especially for maintaining a healthy lifestyle $[15,16]$, the digital divide by age is worrying. In order to enable future planning of the health care system, reliable information on internet usage behavior and its predictors in the older and oldest age groups is becoming increasingly important. In Germany, apart from continuous surveys on general internet use $[17,18]$ and few studies on internet use for health-related purposes $[19,20]$, there is a lack of research investigating the internet use of the older and oldest German population.

There is a yearly survey conducted by a national television broadcaster using telephone interviews to examine internet use and communication in Germany. The 2018 survey of online behavior was conducted with a sample of 2009 German-speaking persons aged 14 and older [17]. However, this study did not examine the determinants of internet use nor did it focus on older and oldest aged individuals. Therefore, the aim of this study is to investigate the frequency of internet use and factors associated with internet use among the German older and oldest aged 75-99. Based on a German population-representative sample, this study focuses on the following research questions:

- Do older and oldest German adults use the internet?

- Do they search the internet for physical or psychological health information?

- Are there differences between internet users and nonusers in old age?

- What are the correlates of internet use in older and oldest age?

\section{Conceptual Framework}

In order to structure the results of this study, we relied on Anderson's behavioral model of health service use [21] and applied this conceptual framework to internet usage. The behavioral model [21] contains 3 main underlying factors: (1) "Predisposing variables" which include demographic and relationship characteristics as well as health perceptions; (2) "Need variables" or the direct cause of service use including the amount and type of disease burden or strain (stressors); (3) "Enabling variables" which are both personal/social resources and community-based resources. This assumes that individuals have the resources and knowledge to know about and use appropriate services. These services must also be available.

\section{Methods}

\section{Study Design and Sample}

We analyzed data derived from the project "Needs assessment in the oldest-old: Application, psychometric examination and establishment of the adapted German version of the Camberwell Assessment of Need for the Elderly (CANE)," which was funded by the German Research Foundation (DFG). Within the project, a population-representative telephone survey was carried out on behalf of the University of Leipzig by a leading market, opinion, and social research institute (USUMA GmbH) in Germany between July and October 2016. The sampling method was based on a procedure implemented by the Association of German Market and Social Research Agency (AMD) and included registered and nonregistered telephone numbers of households throughout Germany. During the first step, individuals aged 75 years and older who lived in randomly selected households were identified as a contact person. In the case of more than 1 person aged 75 years and older living in the contacted household, the kish selection grid was applied in order to randomly select the target person within the household. This method is widely applied for selecting members within a household by using a preassigned table of random numbers to determine the target person. The landline telephone sample used to select the prospective households to be interviewed was converted into a representative population sample by weighting it according to key social demographic characteristics (age, gender, regional distribution by federal state). By applying this technique, equal probability of participation for each member of the randomly selected household, and therefore the representativeness of the sample, was ensured [22]. The detailed sample selection process is presented in Multimedia Appendix 1 and is reported in detail by Stein et al [22].

The survey conducted 1193/2823 (42.26\%) telephone interviews. Interviews were excluded if dementia was suspected as assessed using the Six-item Cognitive Impairment Test (6-CIT) $[23,24]$. In the end, 1004 complete interviews with an average duration of 40 minutes were carried out. For the secondary analyses, the following inclusion criteria had to be met: (1) at least 75 years of age and (2) complete data on relevant variables were available. Additionally, 5 individuals were excluded from the study sample due to missing information or incomplete data on internet usage variables, resulting in an analytical sample size of 999 individuals.

\section{Ethics Approval}

The study was approved by the Ethics Committee of the Medical Faculty of the University of Leipzig. Prior to assessment, all study participants provided informed verbal consent.

\section{Procedure and Instruments}

The survey was conducted using standardized structured computer-assisted telephone interviews, which included sociodemographic variables and several standardized instruments. Prior to the survey, the instruments were tested and adapted within a pretest. Furthermore, the interviewers received comprehensive training. 


\section{Dependent Variables}

The frequency of internet use was measured using a 5-point scale ranging from 1 to 5 ( $1=$ daily, $2=$ at least once a week, $3=$ at least once a month, $4=$ less than once a month, and $5=$ never). In addition, the frequency of internet searches for physical or psychological health information was assessed by using a 4-point scale ranging from 1 to 4 (1=yes, often; 2=yes, sometimes; $3=y e s$, but only rarely; and $4=$ no, never).

\section{Independent Variables}

Based on Anderson's behavioral model [21], explanatory variables were chosen. The predisposing characteristics include age, gender, marital status (married/with spouse, married/living apart, single, divorced, widowed), education, and living situation (living alone in a private household), living with others (spouse/partner, with other relatives, in a nursing home, assisted living situation, retirement home, other).

The need factors included depressive symptoms, health-related quality of life, number of chronic diseases, loneliness, and experiences of loss. Depressive symptoms were measured using the 15-item short German language version of the Geriatric Depression Scale (GDS) [25]. The GDS is used to identify symptoms of depression in older adults (eg, the basic satisfaction with one's life). The scale is a self-report instrument that uses a "Yes/No" format. The short version of the GDS showed good psychometric properties. Reliability coefficient estimated by Cronbach $\alpha$ was .81 for the GDS-15. [26]. According to Allen and Annells [27], a cut-off score on the GDS of $4 / 5$ (noncase/case) correspondents to clinically relevant depressive symptoms and was therefore used in this study to screen participants for depression. The number of chronic diseases was measured by using a list of 22 chronic diseases (eg, high blood pressure, heart attack/coronary heart disease, lung disease, stroke, osteoporosis, diabetes, rheumatism, and cancer) with dichotomous response categories (yes/no). The participants were asked whether or not they had been recently diagnosed by a general practitioner with 1 or more of these chronic medical conditions. Health-related quality of life was assessed by using the Visual Analog Scale of the EuroQol 5-Dimensions 5-Level Questionnaire (EQ-5D-5L Questionnaire) or EQ-VAS [28]. The EQ-5D-5L Questionnaire assesses 5 dimensions of health states (mobility, self-care, usual activities, pain/discomfort, and anxiety/depression). With the vertical visual analogue scale (EQ-VAS) the participant is asked to gauge his or her current health state between best and worst imaginable. The EQ-VAS ranges from 0 (worst imaginable health state) to 100 (best imaginable health state). The EQ-VAS is frequently used as a quantitative measure of self-reported health state and has good psychometric properties in late life [29]. Psychometric properties of the German version of the EQ-5D-5L have been evaluated across different diseases [30-33]. Loneliness was assessed using the 3-item short version of the UCLA (University of California, Los Angeles) Loneliness Scale [34]. The scale captures subjective feelings of loneliness and social isolation (eg, the frequency of lack of company). Participants responded on a 3 -point scale ranging from 1 (hardly ever) to 3 (often). The $\alpha$ coefficient of reliability is .72 , indicating that the 3 -item scale is a reliable measure for loneliness in a telephone survey [34].
Experiences of loss were measured using the Leipziger Lebensereignis-Liste (LLL). The LLL was adapted specifically for older adults and based on previously validated scales for the assessment of stressful life events: Social Readjustment Rating Scale [35], Recent Life Changes Questionnaire [36], and Life Events and Difficulties Schedule [37]. Participants were asked if they had experienced the "death of a significant other" within the last 12 months (yes/no), and if so, who died.

The enabling variables social network/social support were measured using the 6-item Lubben Social Network Scale (LSNS-6) [38]. The LSNS-6 consists of 6 questions assessing the size of the respondent's active social network (ie, number of relatives or friends seen or heard from $\geq 1$ time per month), perceived social support (ie, number of relatives or friends who could be called for help), and perceived confidant network (ie, number of relatives or friends with whom the respondent could talk about private matters). Each LSNS-6 question is scored on a $0-5$ scale. The total social network score is an equally weighted sum of these 6 questions, with scores ranging from 0 to 30 . Higher scores indicate larger social networks or more frequent social contact. It has been demonstrated that the scale has good internal consistency (Cronbach $\alpha=.83$ ) [38].

\section{Statistical Analyses}

Based on population statistics from the German Federal Statistics Office [39], data were weighted by USUMA in accordance with age, gender, and region. In order to obtain population-representative results, USUMA used design and adjustment weighting techniques [40]. In this study, unweighted absolute frequencies were presented, whereas any other analyses were performed and reported by using the weighting factor.

Statistical analyses were conducted using Statistical Package for the Social Sciences (SPSS) version 24.0 for Windows (SPSS Inc.). In the analysis, the variable frequency of internet use was recoded into a dichotomous variable: yes and no. Individuals who reported never using the internet were classified as noninternet users. Individuals who reported using it less than once a month or more were classified as internet users. In addition, the variable frequency of internet searches for physical or psychological health information was recoded into a binary variable yes and no. Further, marital status was recoded into a binary variable (single vs married/with partner), and a new dichotomous variable living situation (living alone/living with others) was created. According to the international education classification "CASMIN" [41], the variable educational level was created with 3 categories (low, middle, and high). Finally, the variable "chronic diseases" was computed by counting the number of chronic conditions. This criterion was met if $75 \%$ or more of the 22 items on the list of chronic conditions were checked positive. If there were more missing values on the list (>15 unanswered items), the question was considered invalid $(\mathrm{N}=1)$.

Descriptive statistics presented are means and corresponding SDs, absolute frequencies, and percentages, as appropriate. The 2 groups (internet users/nonusers) were compared using independent samples $t$ tests (unpaired) or chi-square tests as appropriate. Next, binary logistic regression analyses were conducted to examine factors associated with internet use in 
older adults. The dichotomized variable internet use served as the dependent variable. The predictor variables included age, gender, education, marital status, domicile, experiences of social loss, GDS score, LSNS score, loneliness score, chronic disease, and EQ-5D-5L-VAS score. Furthermore, we performed a binary logistic regression analyses to investigate if health-related conditions are associated with internet search for physical or psychological health information within older internet users. The dichotomized variable internet search for physical or psychological health information (yes/no) served as the dependent variable. The predictor variables included GDS score and number of chronic disease. The significance level was set at $P \leq .05$ for all analyses.

\section{Results}

\section{Participant Characteristics}

Sociodemographic characteristics of the study sample and comparison between internet users and nonusers are presented in Table 1. The sample consisted of 999 individuals; 612 $(59.1 \%)$ were female and $387(40.9 \%)$ were male. The average age was 80.49 , with a range of $75-99$ years. More than one-third of the respondents had a low educational level (368/999, 36.3\%), roughly one-third was highly educated $(324 / 999,31.3 \%)$, and $32.4 \%(307 / 999)$ had a middle educational level.

Table 1. Sociodemographic characteristics of the sample (N=999).

\begin{tabular}{|c|c|c|c|c|}
\hline \multirow[t]{2}{*}{ Variables } & \multirow{2}{*}{$\begin{array}{l}\text { All } \\
(\mathrm{N}=999,100 \%)\end{array}$} & \multicolumn{2}{|l|}{ Internet use } & \multirow[t]{2}{*}{$P$-value } \\
\hline & & Yes $(n=418,41.8 \%)$ & No $(n=581,58.2 \%)$ & \\
\hline Age (years) & & & & $<.001$ \\
\hline Mean (SD) & $80.49(4.69)$ & $78.91(3.57)$ & $81.67(5.07)$ & \\
\hline Range & $75-99$ & $75-92$ & $75-99$ & \\
\hline Gender, $\mathbf{n}^{\mathbf{a}}\left(\%^{\mathbf{b}}\right)$ & & & & $<.001$ \\
\hline Male & $387(40.9)$ & $231(57.5)$ & $156(26.6)$ & \\
\hline Female & $612(59.1)$ & $187(42.5)$ & $425(73.4)$ & \\
\hline Education $^{\mathrm{c}}, \mathbf{n}(\%)$ & & & & $<.001$ \\
\hline Low & $368(36.3)$ & $74(17.7)$ & $294(50.1)$ & \\
\hline Middle & $324(32.4)$ & $142(33.6)$ & $182(31.5)$ & \\
\hline High & $307(31.3)$ & $202(48.7)$ & $105(18.4)$ & \\
\hline Domicile $^{\mathrm{d}}, \mathbf{n}(\%)$ & & & & $<.001$ \\
\hline Alone & $572(55.4)$ & $185(43.3)$ & $387(65.6)$ & \\
\hline With spouse & $378(38.5)$ & $218(53.1)$ & $160(28.4)$ & \\
\hline With relatives & $46(4.5)$ & $17(4.1)$ & $29(4.9)$ & \\
\hline Other & $14(1.5)$ & $4(0.9)$ & $10(1.0)$ & \\
\hline Missing & $1(0.1)$ & $0(0)$ & $1(0.1)$ & \\
\hline Marital status, n (\%) & & & & $<.001$ \\
\hline Married, living together & $353(36.3)$ & $203(49.3)$ & $150(26.6)$ & \\
\hline Married, living apart & $25(2.6)$ & $15(3.8)$ & $10(1.8)$ & \\
\hline Single & $74(7.5)$ & $26(6.4)$ & $48(8.3)$ & \\
\hline Divorced & 77 (7.6) & $28(6.4)$ & $49(8.5)$ & \\
\hline Widowed & $469(46.0)$ & $145(34.0)$ & $324(55.8)$ & \\
\hline Missing & $1(0.1)$ & $1(0.1)$ & $0(0)$ & \\
\hline
\end{tabular}

${ }_{\mathrm{n}}^{\mathrm{n}}$ : frequencies (none weight).

$\mathrm{b}_{\%}$ : percentages (weight).

${ }^{c}$ Educational classification according to the new CASMIN educational classification. Low: inadequately completed general education, general elementary education, basic vocational qualification or general elementary education, and vocational qualification; Middle: intermediate vocational qualification or intermediate general qualification and vocational qualification, intermediate general qualification, general maturity certificate, vocational maturity certificate/general maturity certificate, and vocational qualification; High: lower tertiary education — general diplomas/diplomas with vocational emphasis, higher tertiary education-lower level/higher level [41].

${ }^{\mathrm{d}}$ Multiple responses possible. 


\section{Differences Between Internet Use and Nonuse}

The majority of the sample consisted of internet nonusers (581/999, 57.4\% vs 418/999, 42.6\%, internet users). Of those using the internet, more than one-half searched the internet for physical or psychological health information $(233 / 417,55.7 \%)$. Figure 1 displays the frequency of internet use in general, as well as the frequency of internet use to obtain health-related information.

Figure 1. Frequency of internet use and frequency of internet use to obtain physical or psychological health information.

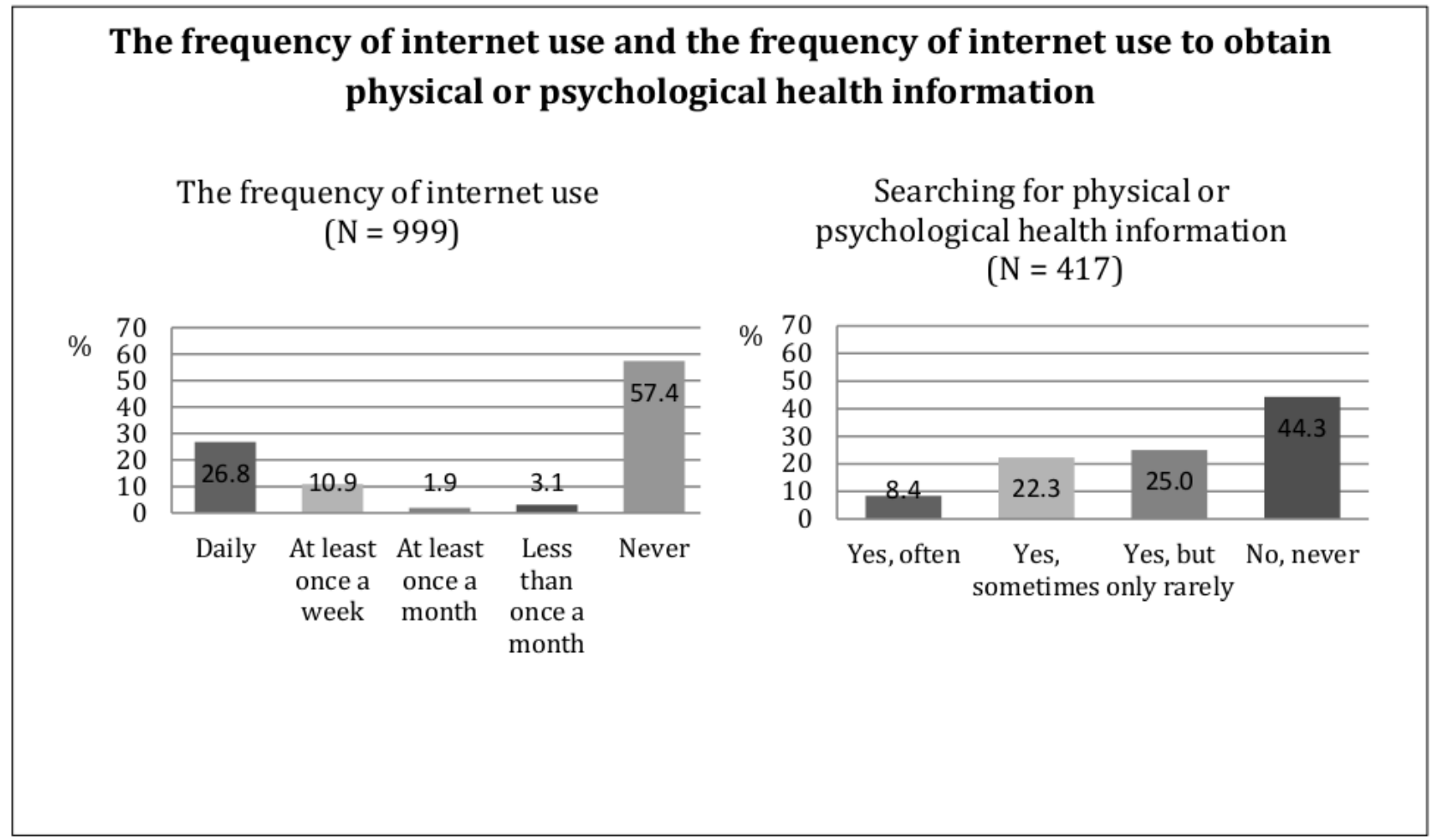

On a group level, there were several differences between users and nonusers, which are shown in Table 1 for sociodemographic variables and in Table 2 for social and health-related factors. In comparison to nonusers, older adults using the internet were more likely to be male $(P<.001)$, tended to be younger $(P<.001)$, were more likely to be middle or highly educated $(P<.001)$, and were more likely to be married/with partner $(P<.001)$ as well as to be living with their partner in the same household $(P<.001)$.
With regard to social and health-related factors, individuals using the internet tended to have better self-rated health-related quality of life $(P<.001)$, reported fewer depressive symptoms $(P<.001)$, fewer chronic medical conditions $(P=.02)$, and less loneliness $(P<.001)$. Furthermore, internet users reported having a greater and more supportive social network than nonusers $(P<.001)$. No significant differences were found regarding experiences of social loss $(P=.87)$. 
Table 2. Social and health outcomes of the sample (N=999).

\begin{tabular}{|c|c|c|c|c|}
\hline \multirow[t]{2}{*}{ Variables } & \multirow{2}{*}{$\begin{array}{l}\text { All } \\
(\mathrm{N}=999,100 \%)\end{array}$} & \multicolumn{2}{|l|}{ Internet use } & \multirow[t]{2}{*}{$P$-value } \\
\hline & & Yes $(n=418,41.8 \%)$ & No $(n=581,58.2 \%)$ & \\
\hline Health-related quality of Life VAS EQ-5D-5L ${ }^{a}$ & & & & $<.001$ \\
\hline Mean (SD) & $73.46(19.51)$ & $78.02(16.48)$ & $70.08(20.87)$ & \\
\hline Range & $0-100$ & $10-100$ & $0-100$ & \\
\hline Missing, $\mathrm{n}^{\mathrm{b}}\left(\%^{\mathrm{c}}\right)$ & $4(0.4)$ & $1(0.3)$ & $3(0.4)$ & \\
\hline UCLA Loneliness Scale $^{d}$ & & & & $<.001$ \\
\hline Mean (SD) & $3.57(1.02)$ & $3.41(0.80)$ & $3.68(1.15)$ & \\
\hline Range & $3-9$ & $3-9$ & $3-9$ & \\
\hline Missing, n (\%) & $15(1.6)$ & $4(0.8)$ & $11(2.1)$ & \\
\hline Experience of social loss & & & & .87 \\
\hline Yes, n $(\%)$ & $297(30.0)$ & $126(30.2)$ & $171(29.8)$ & \\
\hline No, n $(\%)$ & $702(70.0)$ & $292(69.8)$ & $410(70.2)$ & \\
\hline GDS $^{\mathrm{e}}$ & & & & $<.001$ \\
\hline Mean (SD) & $1.81(2.07)$ & $1.27(1.58)$ & $2.21(2.30)$ & \\
\hline Range & $0-13$ & $0-12$ & $0-13$ & \\
\hline Missing, n (\%) & $10(1.0)$ & $5(1.0)$ & $5(0.9)$ & \\
\hline $\operatorname{LSNS}^{\mathbf{f}}$ & & & & $<.001$ \\
\hline Mean (SD) & $15.90(5.97)$ & $17.57(5.52)$ & $14.64(5.99)$ & \\
\hline Range & $0-30$ & $0-30$ & $1-30$ & \\
\hline Missing, n (\%) & $39(4.0)$ & $12(2.9)$ & $27(4.8)$ & \\
\hline Chronic diseases $^{\mathrm{g}}$ & & & & .02 \\
\hline Mean (SD) & $3.58(2.33)$ & $3.37(2.13)$ & $3.73(2.46)$ & \\
\hline Range & $0-13$ & $0-12$ & $0-13$ & \\
\hline Missing, n (\%) & $1(0.1)$ & $0(0)$ & $1(0.2)$ & \\
\hline
\end{tabular}

${ }^{\mathrm{a}}$ VAS EQ-5D-5L: Visual Analogue Scale of the EuroQol 5-Dimensions 5-Level Questionnaire; score ranges from 0 (worst imaginable health state) to 100 (best imaginable health state).

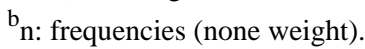

$\mathrm{c}_{\%}$ : percentages (weight).

${ }^{\mathrm{d}}$ UCLA: University of California, Los Angeles, Loneliness Scale; score ranges from 1 (hardly ever) to 3 (often).

${ }^{\mathrm{e}}$ GDS: Geriatric Depression Scale; score ranges from 0 (no depression symptoms) to 15 (depression symptoms), cut-off: $>4$.

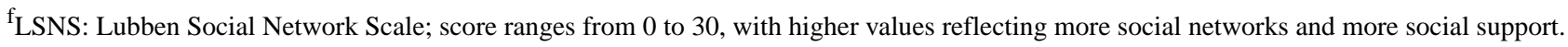

${ }^{\mathrm{g}}$ The sum score of chronic diseases ranges from 0 (no chronic conditions) to 22 (22 chronic conditions).

\section{Predictors of Internet Use}

A binary logistic regression was conducted to identify associations between several factors and internet use (Table 3). Results revealed that younger individuals had significantly higher odds for internet use than older individuals (odds ratio [OR] 0.89, 95\% CI 0.85-0.92; $P<.001)$. In addition, gender was associated with internet use in older age: men were 2.8 times more likely to use internet than women. Furthermore, a higher educational level was significantly associated with internet use among older adults (OR 6.69, 95\% CI 4.48-9.99; $P<.001$ ). Individuals who reported having a greater social network showed a higher chance for internet use than individuals with a smaller social network (OR 1.04, 95\% CI 1.01-1.07; $P=.01$ ). Moreover, individuals with fewer depressive symptoms were 0.9 times more likely to use internet than those with more depressive symptoms. Participants with a better self-reported health-related quality of life had significantly higher odds for internet use than participants with lower self-reported health-related quality of life (OR 1.02, 95\% CI 1.00-1.03; $P=.006$ ). Finally, the number of self-reported chronic diseases was associated with a higher likelihood of internet use among older adults: individuals who had a greater number of chronic diseases had 1.1 times the odds of reporting internet use than individuals with fewer chronic diseases, adjusting for all other sociodemographic and health-related covariates. No significant 
associations between experience of loneliness, experience of social loss, marital status, and domicile and internet use were found. In total, this model explained between $29.3 \%$ (Cox and
Snell) and $39.3 \%$ (Nagelkerke $R^{2}$ ) of the variance in internet use, and substantially improved model predictive power (from $56.8 \%$ to $73.8 \%$ ).

Table 3. Results of binary logistic regression analysis for variables predicting internet use versus nonuse in older adults (N=937).

\begin{tabular}{llll}
\hline & Odds ratio $(95 \% \mathrm{CI})$ & $P$-value & Wald \\
\hline Age & $0.888(0.854-0.924)$ & $<.001^{\mathrm{h}}$ & 34.238 \\
Gender & & \\
$\quad$ Male & $2.842(2.017-4.002)$ & $<.001^{\mathrm{h}}$ & 35.711 \\
$\quad$ Female & Reference &
\end{tabular}

\section{Education $^{\text {a }}$}

Low

Middle

High

\section{Marital status ${ }^{b}$}

Single

Married, living in partnership

Domicile

Alone

Living with others

$\operatorname{GDS}^{\mathrm{c}}$

LSNS $^{\text {d }}$

Health-related quality of Life VAS EQ-5D-5 $\mathrm{L}^{\mathrm{e}}$

Chronic diseases ${ }^{\mathrm{f}}$

UCLA Loneliness Scale ${ }^{\mathrm{g}}$

\section{Experience of social loss}

Yes

No

Constant

Nagelkerke $R^{2}$

Log-likelihood
Reference

$3.813(2.582-5.630)$
$6.691(4.479-9.995)$

Reference

$1.136(0.614-2.100)$

685

0.165

Reference

1.354 (0.741-2.473)

.324

0.973

$0.888(0.795-0.992)$

1.037 (1.008-1.067)

1.015 (1.004-1.025)

1.122 (1.037-1.213)

0.905 (0.748-1.094)

$0.855(0.604-1.212)$

.379

Reference

407.376

.001

11.855

${ }^{a}$ Educational classification according to the new CASMIN educational classification. Low: inadequately completed general education, general elementary education, basic vocational qualification or general elementary education, and vocational qualification; Middle: intermediate vocational qualification or intermediate general qualification and vocational qualification, intermediate general qualification, general maturity certificate, vocational maturity certificate/general maturity certificate, and vocational qualification; High: lower tertiary education-general diplomas/diplomas with vocational emphasis, higher tertiary education-lower level/higher level [41].

${ }^{\mathrm{b}}$ Single: single, divorced, widowed; Married/living in partnership: married/with spouse, married/living apart).

${ }^{\mathrm{c}}$ GDS: Geriatric Depression Scale; score ranges from 0 (no depression symptoms) to 15 (depression symptoms), cutoff: >4.

${ }^{\mathrm{d}}$ LSNS: Lubben Social Network Scale; score ranges from 0 to 30, with higher values reflecting more social networks and more social support.

${ }^{\mathrm{e}}$ VAS EQ-5D-5L: Visual Analogue Scale of the EuroQol 5-Dimensions 5-Level Questionnaire; score ranges from 0 (worst imaginable health state) to 100 (best imaginable health state).

${ }^{\mathrm{f}}$ The sum score of chronic diseases ranges from 0 (no chronic conditions) to 22 (22 chronic conditions).

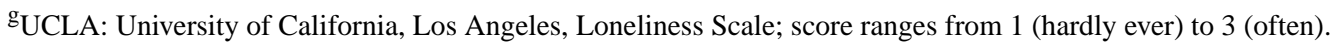

${ }^{\mathrm{h}}$ Significant on the level $\alpha=.001$.

${ }^{\mathrm{i}}$ Significant on the level $\alpha=.05$.

${ }^{\mathrm{j}}$ Significant on the level $\alpha=.01$. 
In order to test the association between health-related factors and the internet use for health purposes among internet users a binary logistic regression was conducted. Neither depressive symptoms (OR 1.10, 95\% CI 0.962-1.260, $P=.164$ ) nor the number of chronic diseases (OR 1.03, 95\% CI 0.932-1.132, $P=.586)$ predicted internet search for health purposes.

\section{Discussion}

\section{Principal Findings}

The aim of this study was to investigate frequency of and factors associated with internet use among individuals aged 75 plus in Germany. Our results revealed that almost half of the 75- to 99-year old reported some internet use. This is comparable to the rates for adults aged 70 plus reported by a population survey on general internet use in Germany in 2016 [17]. Taking into account the trend of internet usage among this age group, there is evidence of a rapid increase of internet users in Germany [17]. Frees and Koch [17] showed that internet usage among this age group is on the rise (up to 65\% in 2018), noting that older adults have the highest increase of daily internet use (from $25 \%$ in 2016 to about $40 \%$ in 2018). Our results confirm these findings-26.8\% (261/999) of the 75-99-year olds used the internet daily. At the same time, we expanded existing data by examining factors related to internet use in older and oldest age. In sum, regression analyses showed that male gender, age, higher levels of education, a more extensive social network, higher level of health-related quality of life, fewer depressive symptoms, and a higher number of chronic diseases increased the likelihood of internet use in this age group.

\section{Possible Explanations and Relation to Previous Studies}

As for predisposing characteristics, the few studies that have focused on older adults (75+) [12,42-44] have shown that internet use in this age is associated with male gender, higher levels of education, being married, and reporting a better health status. In accordance therewith, our findings demonstrate that demographic and socioeconomic status variables are indeed significant predictors of internet use among this age group in Germany. Two of the strongest predictors are male gender and higher levels of education. van Deursen et al [45] showed in their (older adults) sample of internet users and nonusers in the Netherlands that women tend to not make use of the existing internet connection at home. The authors concluded that internet use among older adults seems to be a male-dominated activity. This may be due to the notion that ICT-related skills have been historically stereotypically perceived as more masculine (eg, males are good with technology). Among the older and oldest, such traditional stereotypes may play a more prominent role. However, as Baby Boomers get older, this may change [46], as younger generations of women are more familiar with using the internet and ICT (eg, smartphones).

As for the enabling factor social network/social support, previous studies that examined determinants of internet use among older adults have found that internet users also differ from nonusers with regard to their social embeddedness. Our findings are in accordance with previous research showing that internet users with a more extensive social network are more likely to use the internet [47]. However, due to the correlational nature of this study, no assertion can be made about causality. Therefore, the use of the internet might increase users' social network as measured in this study. Thus, there are other studies which highlight the potential of internet use to enhance or maintain social networks [2] and reduce feelings of loneliness [48] and social isolation [3]. Despite this, and in line with previous studies $[12,45]$, our study found that support from partners, family members, or friends seems to effect the likelihood of going online.

As for need factors, existing studies show associations between internet use and physical/mental health and well-being $[2,8,10,14]$ in this age group. Our findings also reflect this and show that the self-reported health-related quality of life increases the odds for internet use. In addition, a higher number of chronic medical conditions increased the likelihood of internet use in our multivariate analysis. A possible explanation might be the increased need for information about the disease and treatment options. Dumitru et al [19], for instance, noticed that using the internet for health-related purposes is very common (53.7\%) and quickly increasing. Accordingly our findings show that more than half of the interviewees using the internet search on it for physical or psychological health information. Furthermore, findings from several studies show high rates of health-related internet use among those with multiple medical conditions or long-term illness $[15,19]$. However, this contrasts with our finding (ie, no link between internet use for health-related purposes and health-related factors such as the number of chronic medical conditions as well as depressive symptoms). Age seems to be negatively associated with health-related internet use $[19,49,50]$. This may be due to the fact that old and very old people with multiple medical conditions in Germany prefer other sources of information about health or illness, for example, direct face-to-face contacts with physicians and other health care professionals [19].

Common critical life events in older age are social loss experiences along with grief and bereavement, which are considered as risk factors for the development of mental health problems, especially depression and loneliness [51-53]. Whereas individuals with fewer depressive symptoms are more likely to use the internet in this study, no statistically significant effect of experiences of social loss or loneliness on an intensified use of internet among older adults was found. However, this does not necessarily mean older people would not benefit from ICT, for example, internet-based mental health interventions. Research has shown that eHealth (electronic health) interventions may significantly reduce mental health problems in older adults (eg, anxiety and depression [54-56]). Further research targeting this issue is currently being conducted [57].

\section{Strengths and Limitations}

The main strength of this study is the gathering of data from a population-based sample of the general German population aged 75 years and older that can be generalized to other populations in old age. Representativeness was ensured by using design and adjustment weighting methods of the data according to age, gender, and region [40] based on population statistics from German Federal Statistics [46]. However, it should be noted that representativeness may be limited due to the reduction 
of the sample size for analysis and because only community-dwelling older adults with landline telephones, adequate hearing and speech comprehension, and without cognitive impairment were included in the sample. Apart from this, the study has further limitations. First, as the data from the telephone survey offer only a cross-sectional data set, no conclusion about long-term effects and causality can be drawn. Second, we aimed to incorporate many factors that may influence internet use, but, of course, it is likely that there were other unobserved variables at play, for instance, previous internet experiences or internet skills are associated with preferences in internet use in the older age group. Third, the survey is based on self-reported measures; therefore influences such as social desirability cannot be excluded. For more in-depth understanding of the use or nonuse of the internet and the underlying purposes qualitative research might be useful.

\section{Conclusions}

Today, public and private sectors commonly offer online services, which, in turn, have an influence on economic, cultural, and private life. ICT facilities include every day activities such as emailing, online banking, and information seeking, as well as increasingly eHealth services. For example, support via the internet, internet-based therapeutic interventions, and assistive technology are gaining in popularity. Hence, internet-based technologies have become a bigger part of the lives of older adults [58]. Therefore, there is a growing number of studies in this research field focusing specifically on older adults. The studies have identified factors associated with internet usage, as well as benefits and barriers. Moreover, eHealth interventions seem to be promising for promoting older people's well-being by fostering active aging or to helping the elderly stay independent as long as possible. Most of the current research has been mainly focused on younger people or has been limited to pilot studies [59]. Therefore, further research is needed, especially research identifying the types of older adults who would benefit the most from ICT use.

\section{Acknowledgments}

This study was funded by the German Research Foundation under Grant number STE 2235/1-2, and under Grant number RI 1856/4-2. Further, this work was supported by the German Federal Ministry of Education and Research under Grant number $01 \mathrm{GY} 1613$.

\section{Conflicts of Interest}

None declared.

\section{Multimedia Appendix 1}

Study sampling flowchart. [PDF File (Adobe PDF File), 91 KB-Multimedia Appendix 1]

\section{References}

1. Vrkljan B, Montpetit A, Naglie G, Rapoport M, Mazer B. Interventions that support major life transitions in older adulthood: a systematic review. Int Psychogeriatr 2019 Mar;31(3):393-415. [doi: 10.1017/S1041610218000972] [Medline: 29991365]

2. Choi NG, Dinitto DM. Internet use among older adults: association with health needs, psychological capital, and social capital. J Med Internet Res 2013;15(5):e97 [FREE Full text] [doi: 10.2196/jmir.2333] [Medline: 23681083]

3. Chen YR, Schulz PJ. The Effect of Information Communication Technology Interventions on Reducing Social Isolation in the Elderly: A Systematic Review. J Med Internet Res 2016 Jan 28;18(1):e18 [FREE Full text] [doi: 10.2196/jmir.4596] [Medline: 26822073]

4. Gatto SL, Tak SH. Computer, Internet, and E-mail Use Among Older Adults: Benefits and Barriers. Educational Gerontology 2008 Aug 22;34(9):800-811. [doi: 10.1080/03601270802243697]

5. Näsi M, Räsänen P, Sarpila O. ICT activity in later life: Internet use and leisure activities amongst senior citizens in Finland. Eur J Ageing 2012 Jun;9(2):169-176 [FREE Full text] [doi: 10.1007/s10433-011-0210-8] [Medline: 28804417]

6. Medlock S, Eslami S, Askari M, Arts DL, Sent D, de RSE, et al. Health information-seeking behavior of seniors who use the Internet: a survey. J Med Internet Res 2015;17(1):e10 [FREE Full text] [doi: 10.2196/jmir.3749] [Medline: 25574815]

7. Norris SL, High K, Gill TM, Hennessy S, Kutner JS, Reuben DB, et al. Health care for older Americans with multiple chronic conditions: a research agenda. J Am Geriatr Soc 2008 Jan;56(1):149-159. [doi: 10.1111/j.1532-5415.2007.01530.x] [Medline: 18047493]

8. Carpenter BD, Buday S. Computer use among older adults in a naturally occurring retirement community. Computers in Human Behavior 2007 Nov;23(6):3012-3024. [doi: 10.1016/j.chb.2006.08.015]

9. Edwards K, Duffy RM, Kelly BD. The Silver Surfer: Trends of Internet Usage in the Over 65 and the Potential Health Benefits. Ir Med J 2015 Jun;108(6):171-174. [Medline: 26182799]

10. Bujnowska-Fedak MM, Mastalerz-Migas A. Usage of medical internet and e-health services by the elderly. Adv Exp Med Biol 2015;834:75-80. [doi: 10.1007/5584_2014 74] [Medline: 25315621] 
11. White H, McConnell E, Clipp E, Bynum L, Teague C, Navas L, et al. Surfing the Net in Later Life: A Review of the Literature and Pilot Study of Computer Use and Quality of Life. J Appl Gerontol 2016 Jun 29;18(3):358-378. [doi: $10.1177 / 073346489901800306]$

12. Friemel TN. The digital divide has grown old: Determinants of a digital divide among seniors. 2014 Jun 12;18(2):313-331. [doi: $10.1177 / 1461444814538648$ ]

13. Hargittai E, Dobransky K. Old Dogs, New Clicks: Digital Inequality in Skills and Uses among Older Adults. CJC 2017 May 23;42(2):e1. [doi: 10.22230/cjc.2017v42n2a3176]

14. Hunsaker A, Hargittai E. A review of Internet use among older adults. 2018 Jul 16;20(10):3937-3954. [doi: $10.1177 / 1461444818787348]$

15. Crabb RM, Rafie S, Weingardt KR. Health-related internet use in older primary care patients. Gerontology 2012;58(2):164-170. [doi: 10.1159/000329340] [Medline: 21734360]

16. Tse MMY, Choi KCY, Leung RSW. E-health for older people: the use of technology in health promotion. Cyberpsychol Behav 2008 Aug;11(4):475-479. [doi: 10.1089/cpb.2007.0151] [Medline: 18721097]

17. Frees B, Koch W. ARD/ZDF-Onlinestudie 2018: Zuwachs bei medialer internetnutzung und Kommunikation. Media Perspektiven. 2018. URL: https://www.ard-werbung.de/fileadmin/user upload/media-perspektiven/pdf/2018/ 0918_Frees_Koch_2019-01-29.pdf [accessed 2020-07-13]

18. Wirtschaftsrechnungen: Private Haushalte in der Informationsgesellschaft - Nutzung von Informations- und Kommunikationstechnologien 2018. Statistisches Bundesamt. URL: https://tinyurl.com/y45a5u2g [accessed 2019-01-03]

19. Dumitru RC, Bürkle T, Potapov S, Lausen B, Wiese B, Prokosch H. Use and perception of Internet for health related purposes in Germany: results of a national survey. Int J Public Health 2007 Oct;52(5):275-285. [doi: 10.1007/s00038-007-6067-0] [Medline: $\underline{\text { 30311153] }}$

20. Hüfken V, Deutschmann M, Baehring T, Scherbaum W. Verbreitung und Sozialprofil der gesundheitsthemenbezogenen Internetnutzung: Ergebnisse einer bundesweiten Telefonumfrage. Soz -Prventivmed 2004 Dec;49(6):381-390. [doi: 10.1007/s00038-004-3149-0]

21. Anderson R. A behavioral model of families' use of health services. In: Research Series No 25. Chicago: IL: Center for Health Administration Studies, University of Chicago; 1968:xi-111.

22. Stein J, Liegert P, Dorow M, König H, Riedel-Heller SG. Unmet health care needs in old age and their association with depression - results of a population-representative survey. Journal of Affective Disorders 2019 Feb;245:998-1006. [doi: 10.1016/j.jad.2018.11.096]

23. Bickel H, Ambros C, Schulze Beerhorst B. Retrospektive Demenzeinschätzung durch Informantenbefragungen. Ergebnisse zur Validität und zur Inter-Rater-Reliabilität. Zeitschrift für Gerontopsychologie und -psychiatrie 1993;6:175-182.

24. Brooke P, Bullock R. Validation of a 6 item cognitive impairment test with a view to primary care usage. Int J Geriatr Psychiatry 1999 Nov;14(11):936-940. [Medline: 10556864]

25. Gauggel S, Birkner B. Validität und Reliabilität einer deutschen Version der Geriatrischen Depressionsskala (GDS). Zeitschrift für Klinische Psychologie und Psychotherapie 1999 Jan;28(1):18-27. [doi: 10.1026//0084-5345.28.1.18]

26. Almeida OP, Almeida SA. Short versions of the geriatric depression scale: a study of their validity for the diagnosis of a major depressive episode according to ICD-10 and DSM-IV. Int J Geriat Psychiatry 1999 Oct;14(10):858-865. [doi: 10.1002/(sici)1099-1166(199910)14:10<858::aid-gps35>3.0.co;2-8]

27. Allen J, Annells M. A literature review of the application of the Geriatric Depression Scale, Depression Anxiety Stress Scales and Post-traumatic Stress Disorder Checklist to community nursing cohorts. J Clin Nurs 2009 May;18(7):949-959. [doi: 10.1111/j.1365-2702.2008.02731.x] [Medline: 19284431]

28. Herdman M, Gudex C, Lloyd A, Janssen M, Kind P, Parkin D, et al. Development and preliminary testing of the new five-level version of EQ-5D (EQ-5D-5L). Qual Life Res 2011 Dec;20(10):1727-1736 [FREE Full text] [doi: 10.1007/s11136-011-9903-x] [Medline: 21479777]

29. Holland R, Smith RD, Harvey I, Swift L, Lenaghan E. Assessing quality of life in the elderly: a direct comparison of the EQ-5D and AQoL. Health Econ 2004 Aug;13(8):793-805. [doi: 10.1002/hec.858] [Medline: 15322991]

30. Hinz A, Kohlmann T, Stöbel-Richter Y, Zenger M, Brähler E. The quality of life questionnaire EQ-5D-5L: psychometric properties and normative values for the general German population. Qual Life Res 2014 Mar;23(2):443-447. [doi: 10.1007/s11136-013-0498-2] [Medline: 23921597]

31. Hunger M, Sabariego C, Stollenwerk B, Cieza A, Leidl R. Validity, reliability and responsiveness of the EQ-5D in German stroke patients undergoing rehabilitation. Qual Life Res 2012 Sep;21(7):1205-1216. [doi: 10.1007/s11136-011-0024-3] [Medline: 21971874]

32. Stark RG, Reitmeir P, Leidl R, König H. Validity, reliability, and responsiveness of the EQ-5D in inflammatory bowel disease in Germany. Inflamm Bowel Dis 2010 Jan;16(1):42-51. [doi: 10.1002/ibd.20989] [Medline: 19475674]

33. Sonntag M, Konnopka A, Leichsenring F, Salzer S, Beutel ME, Herpertz S, et al. Reliability, validity and responsiveness of the EQ-5D in assessing and valuing health status in patients with social phobia. Health Qual Life Outcomes 2013 Dec 23;11:215 [FREE Full text] [doi: 10.1186/1477-7525-11-215] [Medline: 24365384] 
34. Hughes ME, Waite LJ, Hawkley LC, Cacioppo JT. A Short Scale for Measuring Loneliness in Large Surveys: Results From Two Population-Based Studies. Res Aging 2004;26(6):655-672 [FREE Full text] [doi: 10.1177/0164027504268574] [Medline: 18504506 ]

35. Holmes TH, Rahe RH. The social readjustment rating scale. Journal of Psychosomatic Research 1967 Aug;11(2):213-218. [doi: 10.1016/0022-3999(67)90010-4]

36. Rahe RH. Epidemiological studies of life change and illness. Int J Psychiatry Med 1975;6(1-2):133-146. [doi: 10.2190/JGRJ-KUMG-GKKA-HBGE] [Medline: 773851]

37. Brown GW, Harris T. Social Origins of Depression: A Study of Psychiatric Disorder in Women. London: Tavistock; 1978.

38. Lubben J, Blozik E, Gillmann G, Iliffe S, von Renteln Kruse W, Beck JC, et al. Performance of an Abbreviated Version of the Lubben Social Network Scale Among Three European Community-Dwelling Older Adult Populations. The Gerontologist 2006 Aug 01;46(4):503-513. [doi: 10.1093/geront/46.4.503]

39. Zensus 2011. Statistisches Bundesamt. 2011. URL: https://www.zensus2011.de/SharedDocs/Downloads/DE/Publikationen/ Aufsaetze_Archiv/2015_06_MethodenUndVerfahren.pdf? blob=publicationFile\&v=6 [accessed 2019-01-03]

40. Gabler S, Kolb JP, Sand M, Zins S. Weighting. GESIS Survey Guidelines. 2016. URL: https://www.gesis.org/fileadmin/ upload/SDMwiki/Gabler et al Weighting.pdf [accessed 2019-01-03]

41. Brauns H, Steinmann S. Educational reform in France, West-Germany and the United Kingdom: updating the CASMIN educational classification. ZUMA Nachrichten 1999:7-44 [FREE Full text]

42. König R, Seifert A, Doh M. Internet use among older Europeans: an analysis based on SHARE data. Univ Access Inf Soc 2018 Jan 19;17(3):621-633. [doi: 10.1007/s10209-018-0609-5]

43. Peacock SE, Künemund H. Senior citizens and Internet technology: Reasons and correlates of access versus non-access in a European comparative perspective. Eur J Ageing 2007 Dec;4(4):191-200 [FREE Full text] [doi: 10.1007/s10433-007-0067-z] [Medline: 28794788]

44. Selwyn N. The information aged: A qualitative study of older adults' use of information and communications technology. Journal of Aging Studies 2004 Nov;18(4):369-384. [doi: 10.1016/j.jaging.2004.06.008]

45. van Deursen AJ, Helsper EJ. A nuanced understanding of Internet use and non-use among the elderly. European Journal of Communication 2015 Apr;30(2):171-187. [doi: 10.1177/0267323115578059]

46. Older people in Germany and the EU 2016. Wiesbaden, Germany: Federal Statistical Office of Germany URL: https://www. destatis.de/EN/Publications/Specialized/Population/BrochureOlderPeopleEU0010021169004.pdf?_blob=publicationFile [accessed 2019-01-03]

47. Nahm ES, Resnick B, Mills ME. A Model of Computer-Mediated Social Support Among Older Adults. AMIA Annu Symp Proc 2003:948 [FREE Full text] [Medline: 14728453]

48. Pettigrew S, Roberts M. Addressing loneliness in later life. Aging Ment Health 2008 May;12(3):302-309. [doi: 10.1080/13607860802121084] [Medline: 18728942]

49. Hong YA, Cho J. Has the Digital Health Divide Widened? Trends of Health-Related Internet Use Among Older Adults From 2003 to 2011. J Gerontol B Psychol Sci Soc Sci 2017 Sep 01;72(5):856-863. [doi: 10.1093/geronb/gbw100] [Medline: 27558403]

50. Levine DM, Lipsitz SR, Linder JA. Trends in Seniors' Use of Digital Health Technology in the United States, $2011-2014$. JAMA 2016 Aug 2;316(5):538-540. [doi: 10.1001/jama.2016.9124] [Medline: 27483069]

51. Cacioppo JT, Hawkley LC, Thisted RA. Perceived social isolation makes me sad: 5-year cross-lagged analyses of loneliness and depressive symptomatology in the Chicago Health, Aging, and Social Relations Study. Psychol Aging 2010 Jun;25(2):453-463 [FREE Full text] [doi: 10.1037/a0017216] [Medline: 20545429]

52. Förster F, Stein J, Löbner M, Pabst A, Angermeyer MC, König H, et al. Loss experiences in old age and their impact on the social network and depression- results of the Leipzig Longitudinal Study of the Aged (LEILA 75+). J Affect Disord 2018 Dec 01;241:94-102. [doi: 10.1016/j.jad.2018.07.070] [Medline: 30107351]

53. Sikorski C, Luppa M, Heser K, Ernst A, Lange C, Werle J, AgeCoDe Study Group. The role of spousal loss in the development of depressive symptoms in the elderly - implications for diagnostic systems. J Affect Disord 2014 Jun;161:97-103. [doi: 10.1016/j.jad.2014.02.033] [Medline: 24751315]

54. Jones SL, Hadjistavropoulos HD, Soucy JN. A randomized controlled trial of guided internet-delivered cognitive behaviour therapy for older adults with generalized anxiety. J Anxiety Disord 2016 Jan;37:1-9. [doi: 10.1016/j.janxdis.2015.10.006] [Medline: 26561733]

55. Spek V, Nyklícek I, Smits N, Cuijpers P, Riper H, Keyzer J, et al. Internet-based cognitive behavioural therapy for subthreshold depression in people over 50 years old: a randomized controlled clinical trial. Psychol Med 2007 Dec;37(12):1797-1806. [doi: 10.1017/S0033291707000542] [Medline: 17466110]

56. Titov N, Fogliati VJ, Staples LG, Gandy M, Johnston L, Wootton B, et al. Treating anxiety and depression in older adults: randomised controlled trial comparing guided. self-guided internet-delivered cognitive-behavioural therapy. BJPsych Open 2016 Jan;2(1):50-58 [FREE Full text] [doi: 10.1192/bjpo.bp.115.002139] [Medline: 27703754]

57. Brodbeck J, Berger T, Znoj HJ. An internet-based self-help intervention for older adults after marital bereavement, separation or divorce: study protocol for a randomized controlled trial. Trials 2017 Dec 13;18(1):21 [FREE Full text] [doi: 10.1186/s13063-016-1759-5] [Medline: 28086836] 
58. Wagner N, Hassanein K, Head M. Computer use by older adults: A multi-disciplinary review. Computers in Human Behavior 2010 Sep;26(5):870-882. [doi: 10.1016/j.chb.2010.03.029]

59. Preschl B, Forstmeier S, Maercker A, Wagner B. E-health interventions for depression, anxiety disorders, dementia, and other disorders in old age: A review. Journal of Cyber Therapy and Rehabilitation 2011;4(4):371-385. [doi: 10.5167/uzh-67320]

\author{
Abbreviations \\ AMD: Association for German Market and Social Research Agency \\ CASMIN: CASMIN Educational Classification in International Comparative Research \\ DFG: German Research Foundation \\ GDS: Geriatric Depression Scale \\ ICT: Information and Communication Technology \\ LLL: Leipziger Lebensereignis-Liste \\ LSNS: Lubben Social Network Scale \\ SPSS: Statistical Package for the Social Sciences \\ UCLA: University of California, Los Angeles, Loneliness Scale
}

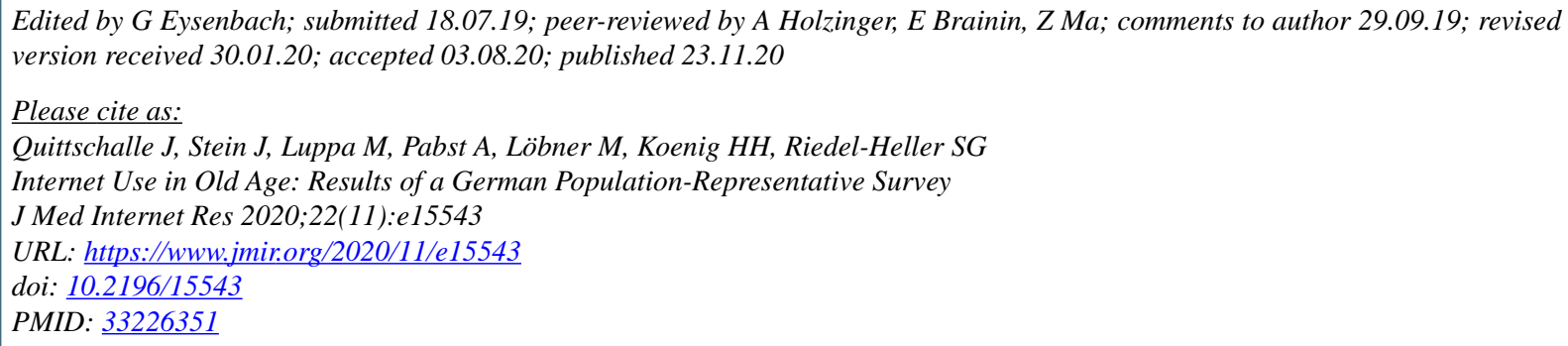

(CJanine Quittschalle, Janine Stein, Melanie Luppa, Alexander Pabst, Margrit Löbner, Hans-Helmut Koenig, Steffi G Riedel-Heller. Originally published in the Journal of Medical Internet Research (http://www.jmir.org), 23.11.2020. This is an open-access article distributed under the terms of the Creative Commons Attribution License (https://creativecommons.org/licenses/by/4.0/), which permits unrestricted use, distribution, and reproduction in any medium, provided the original work, first published in the Journal of Medical Internet Research, is properly cited. The complete bibliographic information, a link to the original publication on http://www.jmir.org/, as well as this copyright and license information must be included. 